\title{
7
}

\section{Individual and organizational effectiveness: Perspectives on the impact of ESS in multinational organizations}

\author{
Sven A. Carlsson
}

Department of Informatics

School of Economics and Management, Lund University, Ole Römers väg 6

S-223 63 Lund, SWEDEN

sven.carlsson@ics.lu.se

Dorothy E. Leidner

Information Systems Department

Hankamer School of Business, Baylor University, P.O. Box 98005

Waco, Texas 76798, USA

Dorothy_Leidner@baylor.edu

Joyce J. Elam

Department of Decision Sciences and Information Systems

Florida International University, University Park Campus

Miami, Florida 33199, USA

elamj@servax

\begin{abstract}
Individual and organizational effectiveness are foundations of Information Systems' theory, research, and practice. In this paper, Quinn and associates' competing values approach (CVA) of organizational effectiveness is used for discussing and assessing the impacts of Executive Support Systems (ESS) on managerial behavior and leadership. It is suggested that an ESS is effective to the extent that it supports top-level managers and executives in promoting organizational effectiveness and that the ESS should effectively support the managers in their different managerial roles. A CVA-based analysis of data from interviews with ESS users in Mexico and Sweden suggests that ESS can support managerial behavior and leadership in different ways. Based on the empirical study and CVA, four archetypes of ESS use are suggested. The study has implications for: 1) ESS theory and research in that it links ESS use to behavioral complexity, and 2) ESS design and implementation in that it suggests a complementary view of the purposes of ESS.
\end{abstract}

\section{Keywords}

Executive Support Systems, Executive Information Systems, Implementation, Effectiveness, Assessment, Leadership, Behavioral Complexity 


\section{INTRODUCTION}

Executive Support Systems (ESS) and Executive Information Systems (EIS) are computerbased information systems that purport to support top-level managers in their work. A growing number of organizations and managers are using ESS/EIS (Fitzgerald, 1992; Watson et al., 1992; Nord \& Nord, 1995). ESS and EIS are Information System (IS) products that are applied to the administrative core of organizations for business administrative process innovations (Swanson, 1994). When such systems are used by top management, their impacts on strategic decision making have the potential of being significant (Rockart \& De Long, 1988; Elam \& Leidner, 1995; Leidner \& Elam, 1995; Leidner et al., 1995; Molloy \& Schwenk, 1995). Research that examines ESS use and the impacts of ESS use is needed.

Research suggests that two requisites of effective leadership are cognitive complexity and well-developed mental models (Bartunek et al., 1983; Streufert \& Swezey, 1986; Weick, 1979; Lord \& Maher, 1991; Isenberg, 1994). The relationship between ESS use and mental models has been addressed. Rockart and DeLong (1988) suggest that ESS by improving access to internal and external data, by combining data from multiple sources, by presenting data in meaningful formats, and by providing analytical capabilities, may enhance senior managers' mental models. An empirical study of roughly 100 EIS users examining the effects of EIS use found that the length of use and/or frequency of use were positively related to mental model enhancement (Leidner et al., 1995). Vandenbosch and Higgins (1995) found in a survey of 73 executives that perceptions of competitive performance resulting from ESS use were strongly related to mental-model building. Mental-model building is the process of changing mental models either to handle disconfirming information or to fit with new environments. Vandenbosch and Higgins did not find any relationship between competitive performance and mental-model maintenance.

Although research suggests that cognitive complexity is a necessary condition for effective leadership, more recent research has questioned whether it is a sufficient condition (Hooijberg \& Quinn, 1991; Hart \& Quinn, 1993; Denison et al., 1995). These researchers suggest that the sufficient condition is "...behavioral complexity which connotes action as well as cognition; that is, effective leadership must be the ability to both conceive and perform multiple and contradictory roles." (Denison et al., 1995). Building in part on these researchers' results and suggestions, this paper will address the linkages between ESS use and executive behavior and leadership.

The competing values approach (CVA), developed by Robert Quinn and associates, provides a comprehensive framework of organizational effectiveness and suggests linkages between managerial behavior and organizational effectiveness. A premise of this paper is that an ESS is effective to the extent that it supports top-managers and executives in promoting organizational effectiveness by providing support for the various managerial roles of managers. This study investigates how top managers in multinational corporations utilize ESS in their management activities. In discussing and assessing the impacts of ESS, the competing values approach is used. This study thus aims to shed some light on the relationship between ESS use, managerial behavior, and organizational effectiveness.

The remainder of the paper is organized as follows: the next section briefly discusses ESS research. It is followed by a section that presents the Quinn et al.'s competing values approach (CVA). Section 4 presents the study and the research methodology. The section following uses the CVA to discuss and assess the effects of ESS use on managerial behavior and 
suggests four archetypes of ESS use. The final section discusses limitations, conclusions, and suggestions for further research.

\section{EXECUTIVE SUPPORT SYSTEMS AND ESS RESEARCH}

Executive Information Systems (EIS) and Executive Support Systems (ESS) are sometimes used interchangeably, but some researchers refer to ESS as systems with a broader set of capabilities than EIS (Rockart \& De Long, 1988). For example, ESS can include modeling and analysis capabilities (e.g., trend analysis, decision support systems and query capabilities) and provide capabilities like electronic communication (e.g., e-mail, computer conferencing, and word processing), and other office information systems capabilities (e.g., automated roledex, tickler files, and electronic calendars). Vandenbosch and Higgins (1995) found that the type of analysis that had a positive impact on executives' mental-model building included: "determining which data will be seen together and hence, which will be compared; selecting presentation formats; manipulating rows, columns, and sort order of reports; and 'mucking around in the data,' calculating single ratios or differences depending on what strikes them as important when they see the numbers." This suggests that the use of analysis capabilities in ESS is rather simple compared to what can be found in advanced Decision Support Systems. In this paper we use the term ESS instead of EIS for the following reasons: 1) it refers to a broader set of capabilities, and 2) the computer-based systems we studied can best be categorized as ESS, i.e., they had ESS capabilities.

Our view of ESS is that it is not a particular type of information technology (IT) in a restricted sense, but primarily a perspective on executives and executive work and on the role of information technology and computer-based systems as executive support tools. There is room for different perspectives on ESS and therefore also room for different ways to assess the effects of ESS use. A problem with ESS theory and research is that the construct ESS implies no specific role or purpose, solely that the ESS supports whatever role the executive follows or has chosen. Other types of systems have clearer roles and purposes -- see, for example, the discussion and definition of Decision Support Systems in Keen and Scott Morton (1978) and Silver (1991). Executives play many different roles and the importance of the roles changes over time. An alternative is to view ESS as support by design. Taking a support by design perspective means that the context where an ESS is to be used has to be understood. It also means that issues of how and when an ESS is to be used have to be raised as well as discussions of impact measures. This will be addressed in Sections 3 and 5.

Past ESS research consists of descriptions of ESS implementations in organizations (Applegate \& Osborn, 1988; Rockart \& De Long, 1988; Osborn \& Applegate, 1989; Houdeshel \& Watson, 1987; Simons, 1992), frameworks for the study of ESS (Millet \& Mawhinney, 1990; Carlsson \& Widmeyer, 1990), development issues (Volonino \& Watson, 1990, 1990-91; Watson et al., 1991; Houdeshel, 1990; Rockart \& De Long, 1988; Walls et al., 1992; Carlsson \& Widmeyer, 1994), and more recently, theory-based studies that examine the impact of ESS from the users' perspective (Leidner \& Elam, 1993-94, 1995; Molloy \& Schwenk, 1995; Vandenbosch \& Higgins, 1995; Leidner et al., 1996; Watson et al., 1995). A general goal when designing and implementing an ESS is that it should lead to effective use. The construct "effective use" forces attention to the dependent variable(s), that is, it forces attention to performance. Discussing, defining, and applying performance variables is essential if the ESS field is to make further inroads into understanding the phenomena involved in 
designing, building, implementing, using, and assessing ESS. Using DeLone and McLean's (1992) IS success framework, one finds that most empirical EIS/ESS studies use as success measures: ESS quality, ESS information quality, ESS use, and/or user satisfaction -- for more extensive reviews of ESS research, see, for example, Sprague and Watson (1996) or Leidner et al. $(1995,1996)$. Based on reviews of EIS/ESS studies, we suggest that more exhaustive studies focusing on individual impact and organizational impact are needed as well as studies that are grounded in management and organization theories.

The study reported in this paper is part of an on-going project on ESS which aims to enhance existing ESS knowledge. In the first phase a survey study in the U.S., Sweden, and Mexico was conducted. It was based on a decision making perspective and hence the generalizations might be limited to that area (Leidner et al., 1996). In the second phase, reported here, a field study was done in several corporations in Mexico and Sweden. One of the purposes of the field study was to focus on factors not covered in the survey study. Carlsson and Widmeyer (1994) have suggested that the competing values approach can be used as one way to conceptualize ESS as well as being a reference theory for an ESS design approach. In this paper we use recent CVA studies as a foundation for discussing and assessing the impact of ESS use.

\section{THE COMPETING VALUES APPROACH AND ESS ASSESSMENT}

Organizational effectiveness is one of the foundations of management and organization theory, research, and practice (Lewin \& Minton, 1986) and it is also central in the IS field (De Lone \& McLean, 1992). Effectiveness is a dependent variable that lies at the very center of all organization theory (Lewin and Minton, 1986). In recent years we have seen different efforts in developing organizational effectiveness constructs. The competing values approach (CVA) was, in part, developed to clarify effectiveness (Quinn, 1988; Quinn and Rohrbaugh, 1981, 1983).

CVA perceives organizations as paradoxical (Cameron, 1986; Quinn \& Cameron, 1988) and it suggests that to achieve high performance requires an organization and its top-managers to simultaneously perform paradoxical and contradictory roles and capabilities (Hart \& Quinn, 1993). The competing values model of organizational effectiveness incorporates three fundamental paradoxes acknowledged in the literature: flexibility and spontaneity vs. stability and predictability (related to organizational structure); internal vs. external (related to organizational focus); and means vs. ends (Quinn \& Rohrbaugh, 1983; Quinn, 1988) -- see Figure 1.

Quinn and Rohrbaugh (1983; Rohrbaugh, 1981) found that most measures of effectiveness reflect one of four organizational models: human relations model, internal process model, rational goal model, or open systems model. The four quadrants in Figure 1 provide competing views on the meaning of organizational effectiveness. The human relations model is characterized by a focus on internal flexibility to develop employee cohesion and morale. It stresses human resource development and participation. The internal process model is characterized by a focus on internal control and uses information management, information processing, and communication to develop stability and control. The rational goal model is characterized by a focus on external control and relies on planning and goal setting to gain productivity and accomplishment. The open systems model is characterized by a focus on 
external flexibility and relies on readiness and flexibility to gain growth, resource acquisition, and external support.

The competing values model points out the simultaneous opposition in the criteria that organizational members use to judge effectiveness. An organization does not pursue a single set of criteria. Instead an organization pursues competing, or paradoxical, criteria simultaneously. Organizations are more or less good in pursuing the criteria, and, according to the CVA, organizations differ in their effectiveness.

The CVA has been used by some researchers in the IS field. McCartt and Rohrbaugh $(1989,1995)$ have used it to assess GDSS and to explain failure and success in implementing GDSS. Carlsson and Widmeyer $(1990,1994)$ have used it to develop a conceptualization of ESS and to discuss how different technological building blocks can be used in building ESS. Stein and Zwass (1995) have used it to suggest how to support organizational memory with information systems.

Human Relations Model

Ends: Value of Human Resources

Means: Cohesion, Moral

\author{
Structure \\ Flexibility \\ Open Systems Model
}

Ends: Resource Acquisition, Growth

Means: Flexibility, Readiness
Ends: Stability, Control

Means: Information Management, Communication

Internal
Stability, Control
s: Information Management,
munication

Internal Process Model

\section{Rational Goal Model}

Figure 1 The competing values model of organizational effectiveness. Adapted from Quinn and Rohrbaugh (1983). 


\subsection{Managerial roles}

Quinn (1988; Quinn et al., 1990) translated the construct of effectiveness into managerial roles (Table 1). Table 1 presents the four organizational models and the associated managerial roles.

INTERNAL PROCESS MODEL: Emphasizes measurement, information management, and information processing; historical and present times oriented; focuses on analyzing static data, cross-sectional data, and giving snapshot views.

- Monitor Role: In this role a manager collects and distributes information (mainly internal and quantitative information), checks performance using traditional measures, and provides a sense of stability and continuity.

- Coordinator Role: In this role a manager maintains structure and flow of the systems, does scheduling, organizes and coordinates activities (logistic issues), solve house keeping issues, and sees that standards, goals and objectives, and rules are met.

RATIONAL GOAL MODEL: Task clarification; goal and objectives setting; decision making; decision implementation (action); achievement oriented.

- Director Role: In this role a manager clarifies expectations, goals and purposes through planning and goal setting, defines problems, establishes goals, generates and evaluates alternatives, generates rules and policies, evaluates performances.

- Producer Role: In this role a manager emphasises performance, motivates members to accomplish stated goals, gives feedback to members, and is engaged in and supports the action phase of decision making.

OPEN SYSTEMS MODEL: Future oriented; analyze cues and information from a dynamic and longitudinal view (a "moving picture" view); multiple focuses; influencing and being influenced by the environment; adaptability and flexibility.

- Innovator Role: In this role a manager interacts with the environment, monitors the external environmental (environmental scanning), identifies important trends, is engaged in business and competitive intelligence (relying on induction and intuition), develops mental models, convinces others about what is necessary and desirable, facilitates change, and shares "image and mental models."

- Broker Role: In this role a manager obtains external resources, is engaged in external communication, tries to influence the environment, and maintains the unit's external legitimacy through the development, scanning, and maintenance of a network of external contacts.

HUMAN RELATIONS MODEL: Process-oriented; stresses cohesion, consensus and healthy conflicts, and teamwork; human resources and the development of commitment; information sharing and participative decision making.

- Facilitator Role: In this role a manager fosters collective effort, tries to build cohesion and teamwork (building the trustful organization), facilitates participation and group problem solving and decision making, pursues "moral" commitment, and is engaged in conflict management.

- Mentor Role: In this role a manager is engaged in the development of people by listening and being supportive, is engaged in the development of individual plans, and gives feedback (for individual development).

Table 1 Key characteristics of the four organizational models and the associated managerial roles -- adapted from Quinn (1988), Quinn et al. (1990), and Denison et al. (1995). 
The descriptions of the organizational models and the associated managerial roles focus on aspects related to managerial behavior and information and knowledge work.

After Quinn and Rohrbaugh's initial studies, work on CVA has proceeded. The CVA model has been validated (Quinn, 1988), and used to study executive leadership (Quinn, 1988; Hart \& Quinn, 1993) and overall organizational effectiveness (Hart \& Quinn, 1993). Recent research suggests that effective executives are capable of balancing and performing contradictory and complex roles (Hart \& Quinn, 1993; Hart \& Banbury, 1994) such as being both opportunistic and strategic. The focus of some studies has been on explaining why some executives are considered more successful than others (Quinn, 1988). More recent research suggests that it is possible to link executive behavior to firm performance; for example, Hart and Quinn's (1993) study suggests that executives that have the ability to play multiple and competing roles produce better firm performance, especially with respect to organizational growth and innovation (business performance) and organizational (stakeholder) effectiveness. In a recent study, Denison et al. (1995) empirically tested the CVA model and the associated roles. They found support for the model and the roles, especially for managers that were considered high performing. Denison et al.'s (1995) work has led them to define effective leadership as "...the ability to perform the multiple roles and behaviors that circumscribe the requisite variety implied by an organizational or environmental context." (Denison et al., 1995).

From our point of view, the CVA model and the research derived thereof have several characteristics fruitful to explore from an ESS perspective. First, they are related to a critical construct: organizational effectiveness. Second, they have a paradox and complexity perspective on effectiveness and managerial roles enabling an explanation of contradiction deemed necessary in recent research (Robey, 1995). Third, the effectiveness construct has been translated into managerial roles, problem orientations, and managerial behavior. This makes it possible to discuss how ESS can be used to support top-level managers in their different roles. Lastly, they point out that not all ESS are equally effective.

Based on the CVA, we suggest that an ESS is effective to the extent that it promotes organizational effectiveness by supporting managers in their varied managerial roles. Our definition of effective ESS use has implications for how learning is perceived. Several researchers have defined learning as being primarily cognitive. Huber says that "An entity learns if, through its processing of information, the range of its potential behaviors is changed." (Huber, 1991). This definition of learning was used by Vandenbosch and Higgins (1995). They said that an ESS user had learned if system use had led to the potential for change in performance. Based on our definition of effective ESS use we suggest that learning is both cognitive and behavioral, that is, an ESS user learns if system use leads to the potential for change in performance (cognitive) as well as actual behavioral change.

\section{RESEARCH METHODOLOGY}

As said, this paper reports on an on-going study of ESS. In the first phase a survey study was carried out. Data was collected from approximately 300 ESS users in the U.S., Mexico, and Sweden -- approximately 100 users from each country. The questionnaire collected data on personal decision making styles, reasons for ESS development, ESS use, and the users' perceptions of the benefits gained from using ESS (Leidner et al. 1995, 1996). In the second phase, ESS users and developers were interviewed. This paper is based on interviews done in 
four Mexican and four Swedish organizations. Typically, at least three persons were interviewed in each organization including at least one top-level manager and the IS manager responsible for the ESS. We used open-ended, semi-structured questions. Each interview was conducted by at least two interviewers. The interviews were tape recorded and transcribed. Secondary data like annual reports, company presentations, and EIS project descriptions and evaluation were also collected.

The transcribed interviews, personal notes from the interviews, and secondary data provide the data that were analyzed -- the main source was the transcribed interviews. An interview transcript is a text. There are different text analysis methods. Lacity and Janson (1994) suggest that IS researchers could use positivist approaches, linguistic approaches, and interpretive approaches in analyzing texts. We chose an interpretive approach. Given a text, several different interpretations, based on different approaches, can be made (Wolcott, 1990). Our intention is to do several analyses and also to examine what the different interpretations give. The next section presents and discusses our first interpretation.

Although the methodology is most appropriately labelled field study as the data were not collected longitudinally, we followed procedures suggested for case study research in designing the study. Following Sanders (1982), the three components in our study design were: 1) determining the limits of what and who is to be investigated, 2) data collection, and 3) analysis of the data. In the analysis we followed the four levels described by Sanders (1982): 1) description of the phenomena, 2) identification of themes or invariants, 3) development of noetic/noematic correlates -- the what (noema) and how (noesis) of experience, and 4) abstraction of essences or universals from the noetic/noematic correlates. We used Sanders' four levels although our approach differed on one important aspect: the use of theories. Sanders approach is in line with traditional phenomenological approaches which say that theories should be developed directly from field data. The difference in approaches is related to a key question in empirical research: the role of theories. Eisenhardt (1989) discusses the use of theories in case studies. She suggests three ways to use theories: (1) as a guide in designing a study and data collection; (2) as a part in an iterative process of data collection and analysis where the first theories are enhanced, expanded, and modified -- in same cases even abandoned altogether; and (3) as a final product of the study. This final product can be in the form of constructs, conceptual frameworks, or mid-range theories.

In designing the survey study, we borrowed heavily from management theories of executive work with a special focus on decision making. We also used Huber's (1990) propositions on the effects of IT on organizational design, intelligence, and decision making. In designing the field study, we used the results of the survey study and added other theories, for example, Mintzberg's (1973, 1994) activity view with its ten executive roles, Kotter's (1982) process view with the two key processes -- agenda setting and network building -- and the competing values approach's managerial roles. One reason for incorporating and expanding the theories is that we assumed they would be useful in directing our questions and explaining things found as surprises in the survey study. For example, the survey study suggested that Mexican executives perceived benefits not addressed in the study since they continued to use the ESS despite no significant relationships between perceived benefits and length of use. The benefits perceived by the Mexican executives could have been of a different nature than was addressed by the survey.

The use of theories in interpretive studies, as discussed above, can be compared to Glaser and Strauss' (1967) grounded theory. Glaser and Strauss say that the discovery of theory should be directly from field data and strongly warned researchers against the first type of use 
of theories (in designing a study). They are more comfortable with the other two ways to use theories. Grounded theory has lately been criticized: Layder asserts that researchers can and should use theories in all three ways. He says that the grounded theory must "...break away from its primary focus on micro phenomena. The very fixity of this concentration is a factor which prevents grounded theory from attending to historical matters of macro structure as a means of enriching ... research on micro phenomena" (Layder, 1993).

\section{RESULTS AND DISCUSSION}

A central question in this study is: Are there archetypes of effective ESS use? To investigate this question, we looked for patterns of different ESS use in relation to managerial roles. We concurrently strove to assess the organization's situation, for example, if it was trying to change its vision and strategy or if it had a fairly clear and stable strategy and vision. Our field study data indicated two distinct visions of ESS: one, as a personal productivity tool; the other, as an organizational change tool. The personal productivity vision coincided with a fairly clear and stable organizational culture and strategy whereas the organizational effectiveness vision coincided with a view to change the organization's culture and strategy. Within each of these two visions, we found examples of systems that supported a great many managerial roles as well as systems that supported very few organizational roles such that the following grid of ESS effectiveness emerges:

\section{Purpose of the ESS}

\begin{tabular}{l|l|l|}
$\begin{array}{l}\text { Organizational } \\
\text { change }\end{array}$ & $\begin{array}{l}\text { Moderately } \\
\text { effective }\end{array}$ & $\begin{array}{l}\text { Highly } \\
\text { effective }\end{array}$ \\
\hline & Few roles supported & Many roles supported
\end{tabular}

Extent of support for managerial roles

Figure 2 Grid of ESS effectiveness. 


\subsection{Organizational ESS: A view to change}

Organizational ESS were those built in response to a perceived need to enable the organization to cope with environmental uncertainty and turbulence. ESS were seen as a way of inculcating a new organizational vision and as a way of shaping organizational culture. Three of the systems in Mexico and one of the Swedish systems are classified as organizational ESS.

Of the four organizational ESS, two were highly effective in that they addressed virtually every managerial role presented in Table 1 . These two systems had very widespread use across divisions and downward in the organization and showed a balance of information in the four quadrants. Both organizations with organizational ESS were large multinational manufacturers. The average number of users in each of the two companies was 200.

In terms of the monitor role, these systems provided finance and sales information as well as daily production and inventory information. This helped the managers maintain control over their organizations and focus individuals on the success factors important to them. One of the systems was organized around ten critical success factors that could be viewed in terms of a selected product by a selected region across a selected time frame. The data was gathered real time from the chosen region, be it in South or Latin American, or Spain where the organization had divisions, and displayed graphically in less than ten seconds. It is felt in these organizations that managers will focus on the success factors that are being monitored closely by top managers.

In terms of the coordinator role, the uniformity of reports in the systems facilitated coordination across functions. For example, one manager stated that "if we need to present information to stockholders we can sometimes have a view ahead of what is going to happen in the next month like maybe the flat division's plant is thinking about having maintenance so maybe in the next month it is going to be lower in sales so he deals with that and informs our CFO. So if we are trying to ask for some loans or some other thing then we need to take into account that situation." Thus, the information contained in the system assisted in coordination not only within divisions and departments, but across divisions and departments. Furthermore, according to one division President, the ESS helped reduce the need for coordination. He stated that "if you leave a problem out of hand, then you have a lot of coordination and a lot of conflict among the functions. If you tackle the problem when it is just marginal, then hopefully it is also easier to solve. So, in a way, the ESS also helps you avoid the conflict." The attitude in both organizations with organizational ESS was that the more users in the more divisions worldwide, the better the coordination. Said one of the controllers in one of the organizations: "It is very difficult to have some uniformity in reports with a lot of divisions if we don't have a system that is for everyone." The goal from the inception of the ESS was to provide information to as many managers worldwide as possible. In addition, electronic mail was seen in both organizations as a means of improving coordination. One of the two organizations had 2000 employees using electronic mail. They hoped to shift from an autocratic management style to a more consultative style and were using the shared vision provided by the ESS as well as the electronic communication provided therewith to encourage this change.

In terms of the director role, the ESS was seen to help the organization achieve quality leadership objectives. The ESS provided planning and budgeting information as well as marketing and price information for use in strategic planning. In terms of the producer role, the ESS helped in that it gave feedback to subordinates concerning whether or not they were meeting goal performance. In one of the organizations, the CEO had a monthly "direction" meeting in which all the people who reported directly to him attended. He explained during 
this meeting his assessment of organizational performance during the past month and presented the main indicators he was examining as well as his interpretation. He used the ESS during the meeting to display his thoughts and encourage the subordinates to make necessary improvements in the coming month.

In terms of the broker and innovator roles, the ESS provided external information about the industry, business cycles, and the purchasing profiles of customers. In one of the organizations, the CEO was attempting to make the company a publicly traded company in the US. For this reason, he wanted to "know every single movement that is happening in the company each month" so as to enable him to have explanations for potential lenders. One of the CEO's subordinates stated his view that the CEO's "main target for using the ESS is to be well prepared to answer the questions of the lenders." The ESS was also used to assist with important decisions such as deciding on whether to close a plant, whether to implement price increases or decreases, and what type of product mix to produce each month. The other organization with an effective organizational ESS was growing by acquisition. Each time an acquisition was made, the systems in the acquired organization were immediately replaced with the systems of headquarters and the acquired company's information was incorporated into the ESS for monitoring. This allowed the newly acquired organization to be quickly initiated to the vision and style of headquarters (though not always without some resistance over the massive and sudden changes introduced by headquarters). The company is currently pushing to include more information about customers and even linking certain modules of the ESS to customers so that major customers themselves will be able to check the status of their orders.

Lastly, in terms of the facilitator and mentor roles falling under the Human Relations Model, the organizational ESS were designed to provide human resource information. The human resource information was used, for example, when the Director of Personnel needed to consider whether to eliminate positions or relocate individuals within the organization to another position. One of the director's of planning was having to considerably downsize the organization. He stated that before he had the ESS, he was unable to obtain information about employees without word rapidly spreading concerning whom he was considering for the layoff. The ESS greatly facilitated his role by enabling him to search for employee information without having to ask for it. In one of the organizations, employee satisfaction surveys were conducted each year. The survey had been developed by industrial psychologists for this organization. The responses were included in a human relations module in the ESS. Each manager could see his subordinate's responses as well as the satisfaction of the subordinates of other managers. The other organization had an holistic view of the ESS as engendering a certain management style which endowed the organization with a competitive advantage. Human resources were viewed in this organization as the basis on which the organization competed. The ESS was viewed as a means of inculcating the desired management style.

In summary, two of the organizations comprising the field study exhibited ESS with a view to organizational change. Both of the ESS supported a wide variety of managerial roles and were widely used in the organization.

Two other organizational ESS were noted but these were not yet able to support a wide variety of managerial roles but were rather concentrated on only a few roles. Both systems, though, demonstrated great potential for radical organizational influence. The Mexican organization, with 10 users, is part of an organization with 100 divisions worldwide. The Swedish organization, with 70-80 users, has operations in over 20 countries. The Mexican organization clearly viewed the ESS as a part of their turnaround strategy. A manager here 
described the organization's environment before NAFTA as follows: "before NAFTA was like a kid riding a bike with training wheels -- it was hard to fall down." The removal of the training wheels brought many a Mexican organization to their knees. In this organization, the goal was to spread a new culture, one that emphasized profits rather than volumes sold. This company found that they were unable to eliminate unprofitable product lines after the opening of the market because they did not have information available on which products were generating profits and which were not. The only information available was volumes sold. It comes as no surprise then that this organization began with a focus on measuring profitability of products in support of the monitor role. The system had not yet spread to lower levels but the President of one of the divisions stated that a goal was to begin getting information downward in the organization in order to encourage subordinates to become more proactive in responding to the increased competition.

The second of the organizational ESS we classify as moderately effective was found in one of the Swedish organizations. This organization had many users -- 70 to 80 -- who used the system primarily to access and review external information, reflecting the goal of improving the organization's competitive response with the ESS. The organization had a link to several external databases. In addition, the organization distributed yearly customer satisfaction surveys the responses to which were entered into the ESS. These surveys were considered an important tool in improving customer service in an increasingly competitive industry. This company had adopted a strategy of growth by acquisition. To facilitate this strategy, a computer-based Du Pont model was incorporated into the ESS and used by the executives for assessing the effects of potential company acquisitions. The system was used to assess several acquisition decisions per month. A positive effect of this type of use is that the ESS can be used for generating and evaluating alternatives, running simulations, and conducting quantitative analyses. Interestingly, in this organization, internal information was less widely used and only available in monthly figures perhaps reflecting a less time pressed management philosophy.

In summary, the two moderately effective organizational ESS were both viewed as important tools in helping the organization respond to a demanding environment, but were both vary narrow in their support of managerial roles which limited the ability of the ESS to facilitate change. However, both systems had widespread top management support and were well-positioned to become highly effective in the future.

\subsection{Personal ESS: A view to personal productivity}

The ESS classified as personal ESS were built for the primary reason of making information available to managers. These systems tended to change very little over time. Several of these systems provide information in support of most of the managerial roles proffered earlier but the systems are not used in such a manner as to inculcate or force organizational change but rather as a means of remaining stable.

Of the four organizations with personal ESS, one demonstrated a good balance of information across the managerial roles. This system contained market information, competitor information, and annual competitor reports. In addition, the system contained internal accounting and financial figures for all divisions in their worldwide operations. However, with only 15-20 users in a company of 9000 across 50 countries, organizational impacts are unlikely. The users interviewed widely agreed that the ESS was a "tool to increase personal work" and nothing more. Indeed, the purported aim of the ESS in this 
organization was "standardization and structuring of information, coordination of information, and increased knowledge of markets and competitors." This purpose in fact supports several managerial roles and the system as a personal productivity tool was very effective. The users concurred that the "rationalization and coordination of work had improved" and that they were "better informed" about the business than before. However, there was no apparent vision to spread the system either down or across in this organization. They felt the system was there to support a few individuals and it did that very effectively.

The remaining three systems classified as personal ESS were less effective in that they failed to support a variety of managerial roles. Two of these systems were found in multinational Swedish manufacturing organizations; the third, in a multinational food and products company in Mexico. One of the Swedish organization and the Mexican organization had both experienced failure with an initial ESS. Managers in both of these organizations felt intuitively that the ESS should help them respond to competition in their industry. However, in both cases the original ESS fell into desuetude shortly after its inception. Reasons given for the failure included the difficulty of integrating information from the worldwide operations and lack of support from the top managers. The Swedish company was in the process of building a new system focused on customer information, factory information, and product quality information. A prototype was being used by 15 users. The Mexican organization still had some marketing managers using the ESS but had halted any plans to improve the ESS.

The third system labelled less-effective personal ESS was found in another Swedish manufacturing organization. In this company, the system had not experienced failure but had not experienced tremendous use either. Among the ten managers using the ESS, the only perceived change in the availability and quality of information with the ESS was that, after the ESS was built, managers did not have to wait as long to have questions answered. There was no external information or human resource information in the system and only monthly internal information was included. The developer stated that the ESS was not developed in "response to a problem but as a way to make information available to people." When asked whether the ESS provided new information, one manager responded that "it is the same information but maybe you look at it a bit more just because it is easily available." This organization demonstrated little vision for the future of ESS other than it would continue to provide the same information to top managers that before was available only in printed form.

In summary, for the personal ESS, it seems that the distinction between effective ESS use and less effective ESS use is related to provision of modules in support of the majority of the managerial roles. Although we did not gather information on the cost of developing and maintaining the ESS in each of the organizations, it is proposed that personal ESS that require large amounts of human or capital resources are likely to be difficult to justify over the longterm and may consequently fall into desuetude. An extreme case of less effective personal ESS can also be found: non-using managers. This group did not surface in the study since we only interviewed ESS users. The ESS literature has several example of ESS failures where in some cases managers never start using the system or stop using the system (Sprague \& Watson, 1996).

\section{CONCLUSION AND FUTURE RESEARCH}

Rockart \& De Long (1988) suggested that ESS researchers should review the descriptive and prescriptive management and executive literature because "...the views we hold of executive 
work greatly influence how we think about executive support systems" and "...reviewing the literature can help ESS researchers, developers, and users become more conscious of the implicit models they have of the executive function. Only by making these beliefs explicit can we begin to reflect on their influence on ESS design." In this paper we have used Quinn and associates' competing values approach to examine the effectiveness of ESS in organizations. We have suggested that an ESS is effective to the extent that it is used by a manager in such a way as to support the manager in his different managerial roles, and support managerial behaviors that circumscribe the requisite variety implied by an organizational or environmental context. The presented view can be contrasted to the common view of ESS: "the purpose of ESS is to provide an executive easy on-line access to to current information about the status of the organization and its environment". We have explored how the CVA of organizational effectiveness and its associated managerial roles can be used for discussing and assessing the impacts of ESS on managerial behavior. We identified four archetypes of ESS use that were related to effective and less effective managerial behavior. The results and suggestions, although tentative, are promising but further research on Executive Support Systems (ESS) on managerial behavior and leadership is needed.

\section{REFERENCES}

Applegate L., and Osborn, C.S. (1988) Grumman Corporation: business information system. Harvard Case (9-188-061), Harvard Business School, Boston, MA.

Ashby, W.R. (1952) Design for a brain. Wiley, New York, NY.

Bartunek, J.M., Gordon, J.R., and Weathersby, R.P. (1983) Developing "complicated" understanding in administrators. Academy of Management Review, 8(2), 273-284.

Cameron, K.S. (1986) Effectiveness as paradox: consensus and conflict in conceptions of organizational effectiveness. Management Science, 32(5), 539-553.

Carlsson, S.A., and Widmeyer, G.R. (1990) Towards a theory of executive information systems. Proceedings of the Twenty-Third Anmual Hawaii International Conference on System Sciences, (ed. J.F. Nunamaker, Jr.), Vol III, 195-201.

Carlsson, S.A., and Widmeyer, G.R. (1994) Conceptualization of executive support systems: a competing values approach. Journal of Decision Systems, 3(4), 339-358.

Denison, D.R., Hooijberg, R. and Quinn, R.E. (1995) Paradox and performance: toward a theory of behavioral complexity in managerial leadership. Organization Science, 6(5), 524540.

De Lone, W.H., and McLean, E.R. (1992) Information systems success: the quest for the dependent variable. Information Systems Research, 3(1), 60-95.

Eisenhardt, K. (1989) Building theories from case study research. Academy of Management Review, 14(4), 532-550.

Elam, J.J., and Leidner, D.G. (1995) EIS adoption, use, and impact: the executive perspective. Decision Support Systems, 14, 89-103.

Fitzgerald, G. (1992) Executive information systems and their development in the U.K.. International Information Systems, 1(2), 1-35.

Glaser, B., and Strauss, A. (1967) The discovery of grounded theory: strategies for qualitative research. Aldine, Chicago, IL.

Hart, S., and Banbury, C. (1994) How strategy-making processes can make a difference. Strategic Management Journal, 15(4), 251-269. 
Hart, S.L., and Quinn R.E. (1993) Roles executives play: CEOs, behavioral complexity, and firm performance. Human Relations, 46(5), 543-574.

Hooijberg, R., and Quinn, R.E. (1991) Behavioral complexity and the development of effective managers. In Hunt, J. and Phillips, R. (Eds.), Strategic management, Texas Tech University, Lubbock, TX.

Houdeshel, G. (1990) Selecting information for an EIS: experiences at Lockheed-Georgia. Proceedings of the Twenty-Third Anmual Hawaii International Conference on System Sciences, (Ed. J.F. Nunamaker, Jr. and R.H. Sprague, Jr.), Vol III, 178-185.

Houdeshel, G., and Watson, H.J. (1987) The Management Information and Decision Support (MIDS) system at Lockheed-Georgia. MIS Quarterly, 11(1), 13-30.

Huber, G.P. (1990) A theory of the effects of advanced information technologies on organizational design, intelligence, and decision making. Academy of Management Review, 15(1), 47-71.

Huber, G.P. (1991) Organizational learning: the contributing processes and the literatures. Organization Science, 2(1), 88-115.

Isenberg, D.J. (1994) Managerial thinking: an inquiry into how senior managers think. Book manuscript.

Keen, P.G.W., and Scott Morton, M.S. (1978) Decision support systems: an organizational perspective. Addison-Wesley, Reading, MA.

Kotter, J.P. (1982) The general managers. Free Press, New York, NY.

Lacity, M.C., and Janson, M.A. (1994) Understanding qualitative data: a framework of text analysis. Journal of Management Information Systems, 11(2), 137-155.

Layder, D. (1993) New strategies in social research. Polity Press, Cambridge.

Leidner, D.E., and Elam, J.J. (1993-94) Executive information systems: their impact on executive decision making. Journal of Management Information Systems, 10(3), 139-156.

Leidner, D.E., and Elam, J.J. (1995) The impact of executive information systems on organizational design, intelligence, and decision making. Organization Science, 6(4), 645664.

Leidner, D.E., Carlsson, S.A., and Elam, J.J. (1995) A cross-cultural study of executive information systems. Proceedings of the Twenty-Eighth Hawaii International Conference on System Sciences, (Ed. J.F. Nunamaker, Jr. and R.H. Sprague, Jr.), Vol. III, 91-100.

Leidner, D.E., Carlsson S.A., Elam, J.J., and Corrales, M. (1996) Executive information systems in Mexico, Sweden and the United States: the effects of culture on EIS use and benefits. Working Paper, Baylor University, Waco, Texas.

Lewin, A.Y., and Minton, J.W. (1986) Determining organizational effectiveness: another look, and an agenda for research. Management Science, 32(5), 514-538.

Lord, R.G., and Maher, K.J. (1991) Leadership and information processing: linking perceptions and performance. Unwin Hyman, Boston, MA.

McCartt, A.T., and Rohrbaugh, J. (1989) Evaluating group decision support system effectiveness: a performance study of decision conferencing. Decision Support Systems, 5, 243-253.

McCartt, A.T., and Rohrbaugh, J. (1995) Managerial openness to change and the introduction of GDSS: explaining initial success and failure in decision conferencing. Organization Science, 6(5), 569-584.

Millet, I., and Mawhinney, C.H. (1990) EIS versus MIS: a choice perspective. Proceedings of the Twenty-Third Anmual Hawaii International Conference on System Sciences, (Ed. J.F. Nunamaker, Jr. and R.H. Sprague, Jr.) Vol III, 202-209. 
Mintzberg, H. (1973) The nature of managerial work. Harper \& Row, New York, NY.

Mintzberg, H. (1994) Rounding out the manager's job. Sloan Management Review, 36(1), 1126.

Molloy, S., and Schwenk, C.R. (1995) The effects of information technology on strategic decision making. Journal of Management Studies, 32(3), 283-311.

Nord, J.H. and Nord, G.D. (1995) Executive information systems: a study and comparative analysis. Information \& Management, 29(2), 95-106.

Osborn, C.S., and Applegate, L.M. (1989) Xerox Corporation: executive support systems. Harvard Case (N9-189-134), Harvard Business School, Boston, MA.

Quinn, R.E. (1988) Beyond rational management: mastering the paradoxes and competing demands of high performance. Jossey-Bass, San Francisco, CA.

Quinn, R.E., and Cameron, K. (Eds.) (1988) Paradox and transformation: toward a theory of change in organization and management. Ballinger, Cambridge, England.

Quinn, R.E., and Rohrbaugh, J. (1981) A competing values approach to organizational effectiveness. Public Productivity Review, V(2), 122-140.

Quinn, R.E., and Rohrbaugh, J. (1983) A spatial model of effectiveness criteria: towards a competing values approach to organizational analysis. Management Science, 29(3), 363377.

Quinn, R.E., Faerman, S.R., Thompson, M.P., and McGrath, M.R. (1990) Becoming a master manager. John Wiley \& Sons, New York, NY.

Robey, D. (1995) Theories that explain contradictions: accounting for the contradictory organizational consequences of information technology. Proceedings of the Sixteenth International Conference on Information Systems, December 10-13, Amsterdam, The Netherlands, 55-63.

Rockart, J.F., and De Long, D.W. (1988) Executive support systems: the emergence of top management computer use. Dow Jones-Irwin, Homewood, IL.

Rohrbaugh, J. (1981) Operationalizing the competing values approach. Public Productivity Review, V(2), 141-159.

Sanders, P. (1982) Phenomenology: a new way of viewing organizational research. Academy of Management Review, 7(3), 353-360.

Silver, M.S. (1991) Systems that support decision makers. John Wiley \& Sons, Chichester, England.

Simons, R. (1992) Asea Brown Boveri: the ABACUS system. Harvard Case (9-192-140), Harvard Business School, Boston, MA.

Sprague, R.H., Jr., and Watson, H.J. (1996) Decision support for management. Prentice Hall, Upper Saddle River, NJ.

Stein, E.W., and Zwass, V. (1995) Actualizing organizational memory with information systems. Information Systems Research, 6(2), 85-117.

Streufert, S., and Swezey, R.W. (1986) Complexity, managers, and organizations. Academic Press, New York, NY.

Swanson, E.B. (1994) Information systems innovation among organizations. Management Science, 40(4), 1069-1092.

Vandenbosch, B., and Higgins, C.A. (1995) Executive support systems and learning: a model and empirical test. Journal of Management Information Systems, 12(2), 99-130.

Volonino, L., and Watson, H.J. (1990) The strategic business functions approach to EIS planning and design. Proceedings of the Twenty-Third Anmual Hawaii International Conference on System Sciences, (Ed. J.F. Nunamaker, Jr.) Vol III, 170-177. 
Volonino, L., and Watson, H.J. (1990-91) The strategic business objectives method for guiding executive information systems development. Journal of Management Information Systems, 7(3), 27-39.

Walls, J.G., Widmeyer, G.R., and El Sawy, O.A. (1992) Building an information system design theory for vigilant EIS. Information Systems Research, 3(1), 36-59.

Watson, H.J., Rainer, K., Jr., and Koh, C. (1991) Executive information systems: a framework for development and a survey of current practices. MIS Quarterly, 15(1), 1330.

Watson, H.J., Rainer, K., Jr., and Houdeshel, G. (Eds.)(1992) Executive information systems: emergence, development, and impact. Wiley, New York.

Weick, K.E. (1979) The social psychology of organizing, Second edition. Random House, New York, NY.

Wolcott, H.F. (1990) Writing up qualitative research. Sage, Newbury Park, CA.

\section{BIOGRAPHY}

Sven A. Carlsson, assistant professor at Department of Informatics, Lund University, Sweden. $\mathrm{He}$ has a Ph.D. in Informatics from the School of Economics and Management at Lund University. His research interests include the use of information technology to support both individual and group decision making, strategic information systems, and organizational transformation through information technology. He has been a visiting scholar at University of Arizona, Tucson, and University of Southern California. His articles have appeared in Journal of Management Information Systems, Information \& Management, Journal of Decision Systems, Scandinavian Journal of Information Systems, and international conference proceedings.

Dorothy E. Leidner, assistant professor at Baylor University in Waco, Texas, received her Ph.D. in information systems in 1992 from the University of Texas at Austin where she also received her Master's and Bachelor's degrees. Her research interests include executive information systems, international IS issues, and electronic classroom technologies. She has published in Information Systems Research, Journal of Management Information Systems, Decision Support Systems, MIS Quarterly, Organization Science, and international conference proceedings

Joyce J. Elam is the James L. Knight Eminent Scholar in Management Information Systems in the Department of Decision Sciences and Information Systems, College of Business Administration, Florida International University, Miami, Florida. Before joining the faculty of Florida International University in 1990, she was an associate professor in the College of Business Administration at the University of Texas at Austin, and a Marvin Bower Fellow at the Harvard Business School. Dr. Elam earned her Ph.D. in operations research from the University of Texas. Her research deals with the competitive use of information technology, the management of the information services function, and the use of information technology to support both individual and group decision making. Her articles have appeared in such journals as Information Systems Research, Decision Sciences, Operations Research, and Decision Support Systems. She is co-author of the book, Transforming the IS Organization, published by ICIT Press, Washington, D.C. She has served as associate editor for MIS Quarterly and is currently on the editorial board for Information Systems Research. 